\title{
Determination of heavy metals in eyeshadows from China
}

\author{
Lesław Świerczek $^{1} \cdot$ Bartłomiej Cieślik $^{1} \cdot$ Adrianna Matysiak $^{1} \cdot$ Piotr Konieczka $^{1}$
}

Received: 26 February 2019 / Revised: 8 June 2019 / Accepted: 17 June 2019 / Published online: 14 August 2019

(c) The Author(s) 2019

\begin{abstract}
Personal care products and cosmetics are used daily by many people, causing local exposure to certain chemical substances through the application directly inside the oral cavity, on the skin, lips, eyes, and mucosa. Eyeshadows are among the most commonly used types of cosmetics. According to scientific reports, they may contain heavy metals, especially in non-original products. The exposure to said heavy metals may cause local skin irritation, sensitization, and allergy. Due to the fact that they are applied around the eyes, where the skin is relatively thin, it is likely that heavy metals can get into the bloodstream which may pose a threat to consumers' health. In the described research, the analysis of eyeshadows from two palettes of generic alternatives to the original eyeshadows was presented. The determination of $\mathrm{Zn}, \mathrm{Ni}, \mathrm{Cd}, \mathrm{Cu}$, and $\mathrm{Pb}$ was conducted using atomic absorption spectrometry. Based on the analysis of the obtained results, it was shown that the content of some heavy metals in generic eyeshadows exceeds the acceptable standards.
\end{abstract}

\section{Graphic abstract}

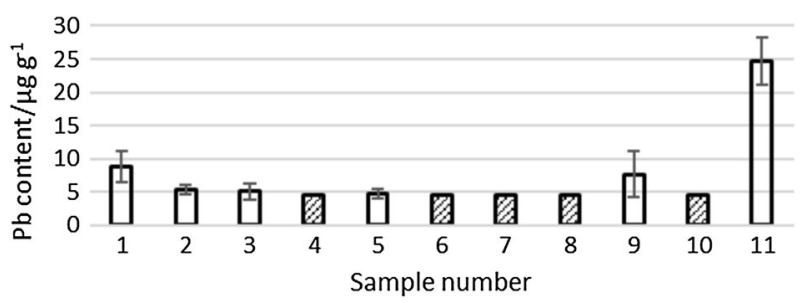

Keywords Metals $\cdot$ Spectroscopy $\cdot$ Pigments $\cdot$ Natural products

\section{Introduction}

Personal care products and facial cosmetics are present in the everyday life of most people. These are usually applied directly to the skin surface, thus causing local exposure to certain chemical substances. Skin is not the only surface through which these substances can get into the body, because such products are also used in the oral cavity, on lips, eyes, and mucosa. For this reason, it is very important to be aware of what kind of potentially harmful substances that such products may contain and of the risk for human health resulting from systematic exposure [1]. Cosmetics

Lesław Świerczek

lesswier@student.pg.edu.pl

1 Department of Analytical Chemistry, Faculty of Chemistry, Gdańsk University of Technology, Gdańsk, Poland include facial and skin care products (creams, deodorants, soaps), color cosmetics (lipsticks, eyeshadows), or hair products (shampoos, sprays) [2]. Due to the variety of substances found in cosmetics (e.g., parabens, phthalates, $p$-phenylenediamine, formaldehyde, triethanolamine, and heavy metals), their use may have detrimental effects on users' well-being. These may include skin irritation, sensitization, allergy, or photoreactions $[1,3,4]$. It is estimated that a statistical woman uses 9-15 different cosmetics every day, which together can contain up to 168 ingredients [5]. According to good manufacturing practices, there is a need for qualitative and quantitative determination of substances that may have a potentially harmful effect on human health [6].

In the European Union countries, according to the Directive 76/768/EEC, cosmetics, under normal conditions of use, must not cause damage to human health and their ingredients 
must be clearly defined in terms of safety before the products are made available on the market. The Directive specifies approximately 1000 banned substances that cannot be used in cosmetics. According to the Directive, the presence of heavy metals in cosmetics is prohibited due to their possible negative impact on human health. This applies to metals and metalloids such as, $\mathrm{Ni}, \mathrm{Hg}, \mathrm{Cd}, \mathrm{Pb}$, and $\mathrm{Co}$. In some cases, metals such as $\mathrm{Zn}, \mathrm{Ag}, \mathrm{Sr}, \mathrm{Al}, \mathrm{Zr}$, and their compounds are allowed, but their use must meet special restrictions [3]. In July 2013, the mentioned Directive was changed into Regulation (EC) No. 1223/2009, which additionally addressed the issue of the safety assessment of nanomaterials [7]. They can be used widely in emulsifier-free cosmetics due to their ability to stabilize the emulsion $[3,8]$.

The US legislation is slightly less restrictive and permits lead compounds (considering them to be safe) in hair coloring agents. It also permits $\mathrm{As}, \mathrm{Hg}$, and $\mathrm{Pb}$ in the case of color additives [9,10], which, in turn, could be used in eyeshadows - the main focus of study. In Canada, it is permitted to use an even a broader variety of heavy metals and metalloids, such as $\mathrm{Pb}, \mathrm{Hg}, \mathrm{Cd}, \mathrm{As}$, and $\mathrm{Sb}$ in cosmetics [11], but their maximum concentrations are also regulated. The permissible heavy metal content under the aforementioned legislation is listed in Table 1.

In the EU, USA, and Canada legal regulations on cosmetics, they precisely define acceptable concentration levels of only a few heavy elements. Literature reports show that cosmetics from some parts of the world may be contaminated with heavy metals $[1,12,13]$, and therefore, it is necessary to constantly monitor their content.

One of the most commonly used cosmetic products which might lead to skin irritation and allergic reactions is eyeshadows. This is due to the fact that pigments and fillers can contain possibly harmful agents, e.g., heavy metals. Their

Table 1 Permissible content of selected heavy metals in cosmetics

\begin{tabular}{llll}
\hline Element & $\begin{array}{l}\text { Legal norm } \\
\text { Content/ } \mu \mathrm{g} \mathrm{g}^{-1}\end{array}$ & & $\mathrm{C}$ \\
\cline { 2 - 4 } & $\mathrm{A}$ & $\mathrm{B}$ & - \\
$\mathrm{Ni}$ & Prohibited & - & 10 \\
$\mathrm{~Pb}$ & Prohibited & 20 & 3 \\
$\mathrm{Cd}$ & Prohibited & - & - \\
$\mathrm{Zn}$ & $10,000^{\mathrm{a}}$ & - & - \\
$\mathrm{Cu}$ & Allowed & - & 3 \\
$\mathrm{Hg}$ & $0.007^{\mathrm{b}}$ & 3 & 3 \\
$\mathrm{As}$ & Prohibited & 1 & \\
\hline
\end{tabular}

A Regulation No. 1223/2009 of the European Parliament

$B$ Regulations by Food and Drug Administration (FDA)

$C$ Regulations by Health Canada (Santé Canada)

${ }^{a}$ As a water-soluble zinc salts-zinc acetate, chloride, and gluconate

${ }^{\mathrm{b}}$ As thiomersal or phenyl mercuric salts in eye product as preservatives main ingredients are talc, appropriate pigments, and zinc or magnesium stearate as a binder. $\mathrm{ZnO}$ is a white insoluble matt powder, which protects against both UV-A and UV-B radiation, has a soothing and astringent effect, and affects the durability of makeup. It is used in foundations, powders, or eyeshadows. Its absorption through the skin is negligible. Magnesium compounds have similar properties. In cosmetics, manufacturing magnesium is mostly used in the form of $\mathrm{MgCO}_{3}$ (pigment and stabilizer) and magnesium stearate (filler) [14]. To obtain the desired color and pearly shine, bismuth oxychloride, mica, or fish scale essence are also used. The metallic effect is obtained using metal and alloy dust containing, e.g., $\mathrm{Cu}, \mathrm{Al}, \mathrm{Au}, \mathrm{Ag}$, or brass $[1,15]$. While nickel compounds should not be used in the production of cosmetics, they might be present as an impurity. They are found in pigments that contain other metals. Regardless of its form, exposure to $\mathrm{Ni}$ is a frequent cause of contact allergies [16, 17]. Cadmium may be an impurity of zinccontaining intermediates, but it could also be added in the production process as a pigment—cadmium sulfide that has an intense yellow color. Toxicity and the ability of local $\mathrm{Cd}$ allergies present in cosmetic products do not depend on the form of its occurrence-the toxicity shows both in the form of the mentioned sulfide and in the metallic form [18, 19]. Lead can be found in cosmetics, e.g., eyeshadows or lipsticks, as a pigment. Using ingredients naturally containing or contaminated with $\mathrm{Pb}$, also during the manufacturing process, may lead to higher concentration in the final product [20]. The above-mentioned additives (e.g., some pigments) are usually of natural origin and can contain heavy metals such as $\mathrm{Cd}, \mathrm{Ni}$, or $\mathrm{Cu}$ and metalloids like As or $\mathrm{Sb}$ [15]. These mentioned might also be introduced into the final product during a poorly designed and performed manufacturing process $[1,2]$.

Toxicity of a substance or element present in a cosmetic product does not only depend on its form or concentration, but also on the place of its application. In the case of colored cosmetics, they are applied on the eyelids, eyelashes, and eyebrows. This creates the possibility of easy penetration through the thin and sensitive skin to the lymphatic system or even directly to the eye. Most often, this happens as a result of blinking, accidental rubbing of the eyelids or when the product is sprayed for application. Eyes, eyelids, and skin in these areas are, therefore, particularly vulnerable to allergies and irritation. In addition, due to the fact that the skin near the eye area is very thin, substances can more easily enter the bloodstream, as mentioned before. They can also easily enter the tear film, causing irritation of the conjunctiva, and tear ducts $[21,22]$. Therefore, EU countries, together with the USA and Canada, are implementing standards to avoid a possible health hazard associated with the use of eyeshadows 
by the consumers. Some specific legislation is listed in Table 1.

Volpe et al., on the basis of their analysis, emphasize that eyeshadows originating from China, unlike products from Italy and the USA, are characterized by higher contents of $\mathrm{Pb}$ (about ten times) and $\mathrm{Ni}$ (in some cases up to 100 times). They also indicate that such products may pose a threat to human health [1]. Similar conclusions were presented by Omolaoye et al., where authors studied 20 different shades of eyeshadows from seven different brands. In all samples, $\mathrm{Ni}\left(77.2-359.4 \mu \mathrm{g} \mathrm{g}^{-1}\right)$, $\mathrm{Cu}\left(1.7-465.0 \mu \mathrm{g} \mathrm{g}^{-1}\right)$, Zn $\left(83.3-342.2 \mu \mathrm{g} \mathrm{g}^{-1}\right)$, Co (122.8-258.3 $\left.\mu \mathrm{g} \mathrm{g}^{-1}\right)$, and $\mathrm{Cr}\left(16.7-150 \mu \mathrm{g} \mathrm{g}^{-1}\right)$ were determined, while the $\mathrm{Cd}$ and $\mathrm{Pb}$ content in most samples was low or below the detection limit of the analytical technique used [23].

Presently, there is a strong tendency in social media to promote prestigious and expensive cosmetics such as eyeshadows. Internet websites and thematic channels contain videos, texts, and reviews for promotion. However, there are many social groups whose financial situation does not allow purchasing the expensive original products. The increasingly popular alternative nowadays is buying such cosmetics from Chinese online retailers. Such products are supposed to look like original products, but can be obtained for a significantly lower price. Since they are ordered by private individuals and not placed on the market in accordance with applicable law, they are not subjected to any tests or controls. Moreover, these types of products lack information on the chemical composition that is required in the European Union according to the International Nomenclature of Cosmetic Ingredients (INCI).

Due to the toxicity and variety of heavy metals found in eyeshadows obtained from China, there is a need for detailed analysis. In this study, two eyeshadow palettes from China, which are imitations, cheaper versions of the original eyeshadows: "Naked Smoky" from Urban Decay and Maybelline's "The Nudes" were subjected to the analysis of heavy metals $(\mathrm{Zn}, \mathrm{Ni}, \mathrm{Cd}, \mathrm{Cu}$, and $\mathrm{Pb}$ ) content using the Flame Atomic Absorption Spectrometry (FAAS) technique. Based on the analysis of the obtained results, it will be possible to determine if the cheaper equivalents of the original eye shadow palettes are safe for the user. The obtained results will help in assessing the possible health risk and safety that is associated with the use of cheaper substitutes for shadow palettes.

\section{Results and discussion}

Eleven colors of eyeshadow samples were analyzed in this study. Comparison between the content of heavy metals in each eyeshadow color is depicted in Fig. 1.
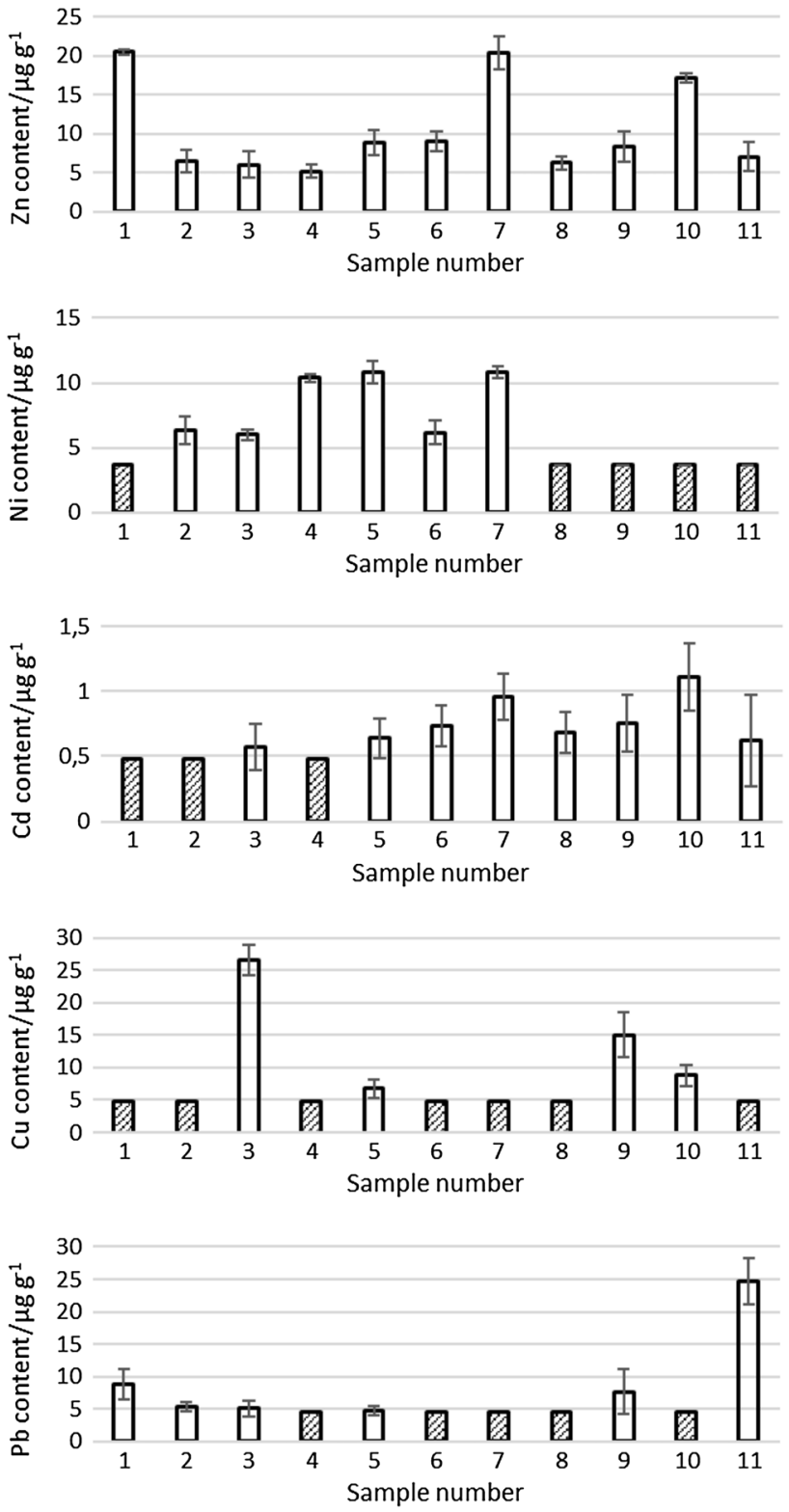

Fig. 1 Heavy metal content in the tested eyeshadow samples

In the case of the "Naked Smoky" (NS) shadows palette, a relation between the color and the concentration of individual elements can be found. Sample 1 contained significant amounts of $\mathrm{Zn}$ and $\mathrm{Pb}\left(20.4 \pm 2.1 \mu \mathrm{g} \mathrm{g}^{-1}\right.$ and $\left.8.9 \pm 2.3 \mu \mathrm{g} \mathrm{g}^{-1}\right)$. The presence of $\mathrm{Zn}$ may indicates that it was used as a binder [14]. High $\mathrm{Pb}$ content compared to other samples and the eyeshadow's dark shade may indicate the use of black lead oxide [3]. Sample 3 had the highest $\mathrm{Cu}$ content of all the analyzed samples $\left(26.6 \pm 2.3 \mu \mathrm{g} \mathrm{g}^{-1}\right)$. As described by Volpe et al., metallic iridescent finish is provided by copper powder [1]. In samples 4 and 5 , the highest concentration of $\mathrm{Ni}$ was found among all samples from the NS palette $\left(10.38 \pm 0.29 \mu \mathrm{g} \mathrm{g}^{-1}\right.$ and $\left.10.80 \pm 0.86 \mu \mathrm{g} \mathrm{g}^{-1}\right)$. 
Table 2 Concentration ranges of selected heavy metals in cosmetics

\begin{tabular}{|c|c|c|c|c|c|c|}
\hline \multirow[t]{2}{*}{ Element } & \multicolumn{6}{|c|}{$\begin{array}{l}\text { Literature } \\
\text { Content } / \mu \mathrm{g} \mathrm{g}{ }^{-1}\end{array}$} \\
\hline & [26] & {$[27]$} & [23] & [1] & [28] & Own research \\
\hline $\mathrm{Ni}$ & - & $19.50 \pm 0.80$ & $77.2-359.4$ & $0.026-4.148$ & $3.9-22.7$ & $3.7-11$ \\
\hline $\mathrm{Pb}$ & $1.9-202.1$ & - & $5.0-55.0$ & $9.53-81.50$ & - & $4.6-25$ \\
\hline $\mathrm{Cd}$ & $0.65-133.10$ & $1.20 \pm 0.10$ & $1.7-6.8$ & $0.00060-0.033$ & - & $0.48-1.1$ \\
\hline $\mathrm{Zn}$ & - & $387.30 \pm 0.60$ & $81.7-342.2$ & - & - & $6.1-21$ \\
\hline $\mathrm{Cu}$ & - & - & $1.7-465.0$ & - & - & $4.8-27$ \\
\hline $\mathrm{Cr}$ & - & $9.56 \pm 0.38$ & $16.7-150.0$ & $0.0007-0.1610$ & $14.0-37.0$ & - \\
\hline
\end{tabular}

Its occurrence in pigments and raw materials used in the cosmetics industry may be connected with its presence in the environment [7]. In sample $2, \mathrm{Ni}\left(6.4 \pm 1.1 \mu \mathrm{g} \mathrm{g}^{-1}\right)$, $\mathrm{Zn}\left(6.5 \pm 1.4 \mu \mathrm{g} \mathrm{g}^{-1}\right)$, and $\mathrm{Pb}\left(5.37 \pm 0.68 \mu \mathrm{g} \mathrm{g}^{-1}\right)$ were detected. In sample 6 , the content of $\mathrm{Zn}, \mathrm{Ni}$, and $\mathrm{Cd}$ was $9.0 \pm 1.3 \mu \mathrm{g} \mathrm{g}^{-1}, 6.19 \pm 0.89 \mu \mathrm{g} \mathrm{g}^{-1}$, and $0.74 \pm 0.16 \mu \mathrm{g} \mathrm{g}^{-1}$, respectively. The contents of the remaining metals in the samples 2 and 6 were below of the limit of quantification (LOQ) and their contents can be considered as trace [24]. Therefore, it should not pose threat to consumers' health. In Fig. 1, these values are shown in the form of hatched bars.

Samples 7 and 10 from "The Nudes" (TN) palette were characterized by the highest $\mathrm{Zn}$ contents $20.4 \pm 2.1 \mu \mathrm{g} \mathrm{g}^{-1}$ and $17.1 \pm 1.3 \mu \mathrm{g} \mathrm{g}^{-1}$, respectively. Despite significant differences in the colors of the eyeshadows, it can be assumed that the zinc compounds in these samples acted as a filler and stabilizer. As in the case of sample 3 from the NS palette, in sample 9, a high concentration of $\mathrm{Cu}$ was observed $\left(15.0 \pm 3.4 \mu \mathrm{g} \mathrm{g}^{-1}\right)$, which can also be associated with obtaining a brilliant effect after the application of the eyeshadow. In sample 8 , such metals as $\mathrm{Zn}\left(6.25 \pm 0.36 \mu \mathrm{g} \mathrm{g}^{-1}\right)$ and $\mathrm{Cd}$ $\left(0.68 \pm 0.16 \mu \mathrm{g} \mathrm{g}^{-1}\right)$ were determined, but the contents of $\mathrm{Ni}, \mathrm{Cu}$, and $\mathrm{Pb}$ were below the LOQ. This elements content can also be considered as trace, and, therefore, safe for the consumers. In sample 11 , the content of $\mathrm{Pb}$ was the highest of all the analyzed samples-24.7 $\pm 3.5 \mu \mathrm{g} \mathrm{g}^{-1}$. Elevated $\mathrm{Pb}$ content can be associated with the use of raw materials with high concentration of this element [7]. Table 2 summarizes the heavy metal content in eyeshadows manufactured in China, reported in the other studies available in the literature.

In comparison to the results obtained by other authors, the content of heavy metals in the studied eyeshadows is lower, but the contents of these metals are high enough to be determined and classified as potentially harmful for the consumer. Bocca et al. suggest that the contents of e.g. Ni, Co, and $\mathrm{Cr}$ in cosmetics should be less than $1 \mu \mathrm{g} \mathrm{g}^{-1}$ to minimize the risk of sensitization in particularly sensitive persons [25].
Table 3 Samples used in the study

\begin{tabular}{llll}
\hline $\begin{array}{l}\text { Sample } \\
\text { number }\end{array}$ & Colour of shadow & Name of palette & Label \\
\hline 1 & Dark blue & Urban Decay "Naked Smoky” & NS \\
2 & Bright silver & & \\
3 & Metallic blue & & \\
4 & Black & & TN \\
5 & Brown-gold & & \\
6 & Light brown & & \\
7 & Black & Maybelline “The Nudes” & \\
8 & Dark brown & & \\
9 & Shiny bronze & & \\
10 & Dark gold & & \\
11 & Brown & & \\
\hline
\end{tabular}

\section{Conclusion}

The use of heavy metals and metalloids in the production of cosmetics is prohibited in the EU countries. However, it does not mean that these elements will be absent in the final product. The referenced EU Regulation No. 1223/2009, which is one of the strictest globally, permits the presence of metals in the final cosmetic products as "technically unavoidable pollution". Nonetheless, based on the non-speciation analysis, it is difficult to decide which of determined elements can be considered as pollution caused by the production process and which as a consequence of the use of contaminated raw materials. During the analysis of all samples of eyeshadows from China, all of the studied elements were determined at various concentrations $(\mathrm{Cd}, \mathrm{Ni}, \mathrm{Cu}, \mathrm{Zn}$, and $\mathrm{Pb})$. Their presence may be related to the use of colored pigments rich in particular elements, but also to the impurities introduced during their production. It is highly probable that the original shadow palettes also contain heavy metals, but, because they are introduced to the European market, these contents are treated as contamination in the legal context. Due to the lack of clear legal restrictions on the content of heavy metals and metalloids in cosmetics in some countries, their content 
Table 4 Basic validation parameters obtained for each analyte using the developed method $\left(R^{2}\right.$ coefficient of determination and $C V$ coefficient of variation)

\begin{tabular}{lllllllll}
\hline Element & Equation & $R^{2}$ & $\mathrm{LOD} / \mu \mathrm{g} \mathrm{cm}^{-3}$ & $\mathrm{LOQ} / \mu \mathrm{g} \mathrm{cm}{ }^{-3}$ & $\mathrm{LOQ} / \mu \mathrm{g} \mathrm{g}{ }^{-1}$ & $\begin{array}{l}\text { Linearity } \\
\text { range/ } \mu \mathrm{g} \mathrm{cm}^{-3}\end{array}$ & Wavelength/nm $\mathrm{CV} / \%$ \\
\hline $\mathrm{Zn}$ & $y=0.2343 x+0.0049$ & 0.999 & 0.037 & 0.11 & 2.5 & $0.11-1.5$ & 213.9 \\
$\mathrm{Ni}$ & $y=0.0988 x+0.0079$ & 0.996 & 0.052 & 0.16 & 3.7 & $0.16-8.0$ & 232.0 \\
$\mathrm{Cd}$ & $y=0.2761 x+0.0065$ & 0.999 & 0.022 & 0.067 & 0.48 & $0.067-1.8$ & 228.8 & 1.8 \\
$\mathrm{Cu}$ & $y=0.0896 x+0.0060$ & 0.997 & 0.069 & 0.21 & 4.8 & $0.21-5.0$ & 324.7 & 1.5 \\
$\mathrm{~Pb}$ & $y=0.3665 x+0.0158$ & 0.999 & 0.071 & 0.21 & 4.6 & $0.021-20$ & 217.0 \\
\hline
\end{tabular}

should be analyzed in original palettes to clearly determine the content of toxic elements in the matrix itself.

The content of heavy metals in the tested eyeshadows exceeds the admissible values specified in the EU regulations. However, most of the mentioned contaminants are at a lower concentration range than those reported in different studies in similar samples [1, 23, 26-28]. One exception is $\mathrm{Pb}$, concentration of which in one sample was relatively high. Therefore, it can be assumed that the analyzed eyeshadow samples (except for sample 11 from the TN palette) contain heavy metals at relatively low levels, but it cannot be ruled out that their presence will have a negative impact on the health of the user.

\section{Experimental}

\section{Sampling}

The eyeshadows used in the study were purchased from one of the online retailers offering inexpensive cosmetics. Eyeshadows imported from China and used in the study were less expensive equivalents of the brand eyeshadows: Urban Decay's "Naked Smoky", and Maybelline's "The Nudes". Eleven different powder shadows were chosen, of which 7 came from the palette of non-original NS shadows, while 5 were chosen from the palette of non-original TN shadows. All samples, together with their colors, are listed in Table 3. Samples were stored at room temperature until the analyses.

\section{Chemicals and standards}

The mineralization of samples was carried out using $65 \%$ $\mathrm{HNO}_{3}$ and $30 \% \mathrm{HCl}$ solution of suprapure grade (Merck, Darmstadt, Germany). Single element commercially available standard stock solutions (Honeywell Fluka Analytical Standards) at the concentration of $1000 \mathrm{mg} \mathrm{dm}^{-3}$ were used to prepare a set of calibration solutions to obtain the calibration curve. The standards were prepared with a serial dilution technique within the range, as shown in Table 4. High-purity deionized water (Milli-Q system, Millipore, Bedford, MA) was used for dilution of samples and standards.

\section{Sample digestion}

About $1 \mathrm{~g}$ of each eyeshadow sample was weighed and transferred into PTFE mineralization container. Subsequently, $10 \mathrm{~cm}^{3}$ of a mixture of $\mathrm{HCl}$ and $\mathrm{HNO}_{3}$ in the volume ratio of 8:2 was added. Wet mineralization was assisted with microwave radiation using a Microwave GO digester by Anton Paar. Mineralization was carried out for $1.5 \mathrm{~h}$ at a maximum temperature of $200{ }^{\circ} \mathrm{C}$. After cooling, the obtained sample solutions were filtered, since $\mathrm{Si}$-bound and $\mathrm{TiO}_{2}$ fractions remained not mineralized. After proper filtration solutions were quantitatively transferred into $25 \mathrm{~cm}^{3}$ volumetric flasks and made up to volume with deionized water. In parallel, a blank sample consisting of digestion mixtures was prepared.

\section{Determination technique}

The pseudo-total concentrations of $\mathrm{Zn}, \mathrm{Ni}, \mathrm{Cd}, \mathrm{Cu}$, and $\mathrm{Pb}$ were determined by Atomic Absorption Spectrometry (SensAA_GBC Scientific Equipment) with acetylene-air flame atomization. The instrument was calibrated with solutions of the prepared standards prior to the analysis. The calibration curve was obtained using at least five standard solutions at different concentrations. The main validation parameters determined for particular analyzed elements are listed in Table 4. Each standard as well as sample solution measurement was replicated tree times. Taking into account the repeatability of reading the value of signals for standard solutions and samples, uncertainty due to the determination of the reference value for standard samples, and approximation of measurement points using regression curve, the uncertainty of the obtained concentrations of heavy metals was determined. Uncertainties are expressed in the form of error bars in Fig. 1. The obtained concentration values were converted into heavy metals per weight of each eyeshadow $\left(\mu \mathrm{g} \mathrm{g}^{-1}\right)$. 
Acknowledgements This research did not receive any specific grants from funding agencies in the public, commercial, or not-for-profit sectors.

Open Access This article is distributed under the terms of the Creative Commons Attribution 4.0 International License (http://creativeco mmons.org/licenses/by/4.0/), which permits unrestricted use, distribution, and reproduction in any medium, provided you give appropriate credit to the original author(s) and the source, provide a link to the Creative Commons license, and indicate if changes were made.

\section{References}

1. Volpe MG, Nazzaro M, Coppola R, Rapuano F, Aquino RP (2012) Microchem J 101:65

2. Regulation (EC) No $1223 / 2009$ of the European Parliament and of the Council of 30 November 2009 on cosmetic products (Text with EEA relevance). https://eur-lex.europa.eu/legal-content/EN/ TXT/HTML/?uri=CELEX:32009R1223\&from=EN. Accessed 28 Jun 2019

3. Borowska S, Brzóska M (2015) J Appl Toxicol 35:551

4. Janečková M, Bartoš M, Lenčová J (2019) Monatsh Chem 150:387

5. Hamilton T, de Gannes GC (2011) Skin Therapy Lett 16:1

6. Marinovich M, Serena M, Testai E, Galli CL (2014) Regul Toxicol Pharmacol 69:416

7. Bocca B, Pino A, Alimonti A, Forte G (2014) Regul Toxicol Pharmacol 68:447

8. Bachinger A, Kickelbick G (2010) Monatsh Chem 141:685

9. FDA (Food and Drug Administration) (2007) CFR - code of federal regulations title 21. Lead acetate. https://www.accessdata .fda.gov/scripts/cdrh/cfdocs/cfcfr/CFRSearch.cfm?fr=73.2396. Accessed 3 Jun 2019

10. FDA (Food and Drug Administration) (2014) Lipstick and lead: questions and answers. https://www.fda.gov/cosmetics/cosmeticproducts/limiting-lead-lipstick-and-other-cosmetics\#initial_surve y. Accessed 3 Jun 2019
11. HC-SC (Health Canada-Santé Canada) (2012) Consumer product safety. Guidance on heavy metal impurities in cosmetics. https ://www.hc-sc.gc.ca/cps-spc/pubs/indust/heavy_metals-metau x_lourds/index-eng.php. Accessed 3 Jun 2019

12. Sani A, Gaya MB, Abubakar FA (2016) Toxicol Reports 3:866

13. Abrar A, Nosheen S, Perveen F, Abbas M (2018) Pak J Sci Ind Res Ser A Phys Sci 61:51

14. Draelos ZD (2001) Clin Dermatol 19:424

15. Hepp NM, Mindak WR, Gasper JW, Thompson CB, Barrows JN (2014) J Cosmet Sci 65:125

16. Oh JE, Lee HJ, Choi YW, Choi HY, Byun JY (2016) J Eur Acad Dermatol Venereol 30:1518

17. Norris MR, Bielory L (2018) Curr Opin Allergy Clin Immunol 18:404

18. Ng A, Evans K, North RV, Jones L, Purslow C (2016) Eye Contact Lens 42:211

19. Balarastaghi S, Khashaiarmanesh Z, Makhdoumi P, Alavizadeh SH, Sameie Moghadam Z, Shirani K, Karimi G (2018) Toxin Rev 37:117

20. Hepp NM, Mindak WR, Cheng J (2010) Int J Cosmet Sci 32:233

21. Malik A, Claoué C (2012) Contact Lens Anterior Eye 35:247

22. Sainio EL, Jolanki R, Hakala E, Kanerva L (2000) Contact Dermatitis $42: 5$

23. Omolaoye JA, Uzairu A, Gimba CE (2010) Arch Appl Sci Res 2:76

24. Baranowska I (2016) Handbook of trace analysis: fundamentals and applications. Springer, New York

25. Bocca B, Forte G, Pino A, Alimonti A (2013) Anal Methods 5:402

26. Ziarati P, Mousavi Z, Shariatdoost A, Ziarati P, Shariatdoost A (2013) J Environ Anal Toxicol 03:525

27. Faruruwa MD, Bartholomew SP (2014) Am J Chem Appl 1:27

28. Contado C, Pagnoni A (2012) Sci Total Environ 432:173

Publisher's Note Springer Nature remains neutral with regard to jurisdictional claims in published maps and institutional affiliations. 